\title{
Mereological Nihilism and Personal Ontology
}

\author{
Andrew Brenner
}

Forthcoming in The Philosophical Quarterly.

\section{Contents}

1 Introduction 1

2 The Objections $\quad 3$

$\begin{array}{lll}3 & \text { Implications } & 18\end{array}$

4 Conclusion $\quad 22$

Abstract: Mereological nihilists hold that composition never occurs, so that nothing is ever a proper part of anything else. Substance dualists generally hold that we are each identical with an immaterial soul. In this paper I argue that every popular objection to substance dualism has a parallel objection to composition. This thesis has some interesting implications. First, many of those who reject composition, but accept substance dualism, or who reject substance dualism and accept composition, have some explaining to do. Second, one popular objection to mereological nihilism, one which contends that mereological nihilism is objectionable insofar as it is incompatible with the existence of people, is untenable.

\section{Introduction}

Mereological nihilism (or just "nihilism") is the thesis that (mereological) composition never occurs. So, if nihilism is correct, then there aren't any composite objects. Substance dualism, as I will understand the thesis, is the claim that we are each identical with an immaterial soul. In this paper I defend, and explore the implications of, the following claim: all of the 
popular arguments against substance dualism can, with minor modifications, be turned into arguments against composition.

In $\S 2$ I describe the parallels between arguments against substance dualism and arguments against composition. In $\S 3$ I explore the implications of this parallelism. There I argue that one implication of the parallelism noted in $\S 2$ is that the following conjunctions of theses are dialectically unstable:

(1) Reject composition and accept substance dualism.

(2) Reject substance dualism and accept composition.

What I mean when I call these conjunctions of theses "dialectically unstable" is that, to take (2) as an example, you should probably not reject substance dualism while accepting composition, insofar as the arguments which probably convinced you to reject substance dualism can, with minor modification, be turned into more or less equally effective arguments against composition. In $\S 3$ I also argue that (2) has a further interesting implication, namely that one popular argument against nihilism is unsuccessful. This argument, what I'll call the "composite persons objection" to nihilism, states that nihilism is false because it has the absurd consequence that we (you, me, people in general) do not exist. But this objection to nihilism relies on the presupposition that substance dualism is false, since substance dualism provides a natural way of reconciling nihilism with the existence of people like you and me. But if the proponent of the composite persons objection rejects substance dualism for the standard reasons - that is, for the reasons discussed in $\S 2$ - then they should feel compelled to endorse the parallel objections to composition. The composite persons objection, then, is unworkable, at least for many of its proponents - those who endorse the objection to nihilism must reject substance dualism, but those arguments which tend to convince these philosophers to reject substance dualism can, with minor modification, be transformed into arguments for nihilism.

Aside from those implications discussed in $\S 3$, you might think the parallels between substance dualism and composition are interesting in their own right. While I don't endorse all of the arguments below, the fact that every major argument against substance dualism finds a parallel argument against composition should give us pause. After all, substance dualism is widely regarded as defunct, for the reasons given below. While the case against substance dualism is, I think, perhaps overblown, let's assume the consensus is correct, that there is an overwhelming case to be made against substance dualism. The upshot of this paper is that, if there is an overwhelming case to be made against substance dualism, then there may also be a strong case to be made against composition. Similarly, and surprisingly, there may be a strong case to be made against any alternative theory of personal ontology 
which identifies us with composite objects. This includes most of the proposed theories of personal ontology, for example those which identify us with animals, brains, particular (non simple) parts of brains, and four-dimensional spacetime worms.

\section{The Objections}

I should emphasize that all of the objections below are sketches. Much more could be said about all of these objections (both the objections against dualism, and the parallel objections against composition). I should also emphasize that I do not endorse all of the objections I am about to discuss. Perhaps you will think one or more of the objections sketched below are very bad objections, or rely on premises we know to be false, and I might very well agree with you.

Above I've said that the objections to dualism discussed below can, with "minor" modification, be transformed into objections to composition. Perhaps you will not think the modifications required are very minor. The claim I am most concerned to defend, however, is not that the modifications required to transform an objection to substance dualism into an objection to composition are "minor" modifications, or even that the similarities between the objections to substance dualism and the parallel objections to composition are very strong. Rather, I am most concerned to establish the claim that if you accept an objection to dualism discussed below, then you should accept the parallel objection to composition as well, since those very same considerations which motivate each objection to dualism also motivate the parallel objection to composition.

Objection 1: Ontological parsimony.

Ontological parsimony is generally thought to come in two varieties: quantitative ontological parsimony, and qualitative ontological parsimony. If either of these sorts of parsimony are taken to be theoretical virtues (in the sense that a theory which exhibits one or both of these sorts of ontological parsimony is thereby more likely to be true) then either sort of parsimony provides the resources for an argument against substance dualism. First, consider quantitative ontological parsimony, according to which a theory displays greater parsimony than one of its competitors if it posits fewer entities. Substance dualists, by positing immaterial souls in addition to the various material objects everyone else posits, have more ontological commitments than non-substance dualists. Accordingly, all other things being equal, if quantitative ontological parsimony is a theoretical virtue, then substance dualism is, in virtue of its diminished quantitative ontological parsimony, less 
likely to be true than its competitors. Qualitative ontological parsimony is parsimony with respect to the kinds of things posited by a theory. Substance dualists posit more kinds of things than most of their competitors, insofar as substance dualists posit the existence of a kind of thing (immaterial things, or at any rate immaterial minds or people) which most of their competitors will not accept (see, e.g. Churchland 1984: 18). ${ }^{1}$

Both sorts of objections - an objection from quantitative ontological parsimony, and an objection from qualitative ontological parsimony - can be made against composite objects. The believer in composite objects posits the existence of more things than nihilists do, since the believer in composite objects posits the existence of various composite objects, while the nihilist does not. Similarly, the believer in composite objects posits the existence of more kinds of things, namely composite objects (objects with proper parts), which the nihilist will not posit. ${ }^{2}$ Accordingly, if quantitative or qualitative ontological parsimony are theoretical virtues, then nihilism receives some confirmation from its relative ontological parsimony. ${ }^{3}$

Note that ontological parsimony, and parsimony more generally, will not be the only factor one takes into consideration when one tries to decide whether substance dualism is correct, or whether composition occurs. The idea isn't, however, that considerations of ontological parsimony, or parsimony more generally, provide a decisive objection to either substance dualism or composition. The idea, rather, is just that their relative lack of ontological parsimony (or parsimony more generally) provide some grounds for thinking substance dualism is false, and for thinking non-nihilist theories are false.

\section{Objection 2: Ideological parsimony.}

${ }^{1}$ An exception being made for theists, and anyone else who already believes in immaterial people.

2Objection: While composite objects are "a new kind of thing" (in contrast to simples), they are not as new, so to speak, as immaterial souls would be. In other words, composite objects are fairly similar to those things which are already included in the nihilist ontology (physical simples), while immaterial souls, since they are immaterial, non-located, etc., are radically different from the material objects included in the typical non-dualist's ontology. Response: Some non-substance dualists will also accept immaterial objects of various sorts (God, numbers, properties, etc.). It is not clear to me, however, how we should judge the extent to which an ontological kind is similar to some ontological kind we already posit, and whether this is even relevant to how we assess the extent to which positing a new ontological kind detracts from the parsimony of our total theory. Why, for example, is the ontological kind "composite physical object" a smaller departure from the ontological kind "simple physical object" than "immaterial soul" is from "material object"? Given this concern, it is difficult to evaluate the strength of this objection.

${ }^{3}$ Horgan and Potrč (2008) defend nihilism in part on the basis of its ontological parsimony. 
Quine (1951) famously distinguished between a theory's ontology and its ideology. Like ontological parsimony, ideological parsimony comes in two varieties, what we might call quantitative ideological parsimony, and qualitative ideological parsimony. ${ }^{4}$ Let's assume both sorts of parsimony are theoretical virtues. A theory exhibits greater quantitative ideological parsimony if it employs fewer primitives, either primitive predicates, or, more generally, primitive expressions. ${ }^{5}$ By contrast, qualitative ideological parsimony is parsimony with respect to kinds of ideological commitments, where, for example, two or more predicates may be of the same kind if they are interdefinable. Substance dualism might exhibit less ideological parsimony than many of its competitors if mental predicates must be taken as primitive (irreducible to non-mental predicates), or if the predicate "immaterial" has to be taken as primitive. Notably, primitive mental predicates will be employed by some non-substance dualists, namely property dualists and possibly neutral monists. Furthermore, the predicate "immaterial" will plausibly not have to be taken as primitive, as long as the predicate "material" (which every non-substance dualist other than idealists will have to employ, presumably) is taken as a primitive.

Ideological parsimony considerations more clearly seem to count against composition. As Sider (2013) has recently argued, nihilists can do without mereological primitives (for example, the two place parthood relation). This is a point in favor of nihilism's quantitative and qualitative ideological parsimony. ${ }^{6}$ Some philosophers argue that nihilism does not enjoy greater ideological parsimony than its competitors, since nihilists will need to employ new predicates like "arranged table-wise" (see, for example, Bennett 2009; Tallant 2014). But that's not right, since the sorts of arrangement predicates employed by the nihilist are also employed by the non-nihilist. After all, some simples will compose a table, for example, precisely because they are arranged table-wise. There's more to be said on this subject (see Brenner 2015a). For now it is enough to note that the nihilist has a prima facie plausible case to make that her view enjoys greater ideological parsimony than its competitors.

\footnotetext{
${ }^{4}$ Qualitative ideological parsimony was brought to philosophers' attention in Cowling 2013.

${ }^{5}$ E.g. logical connectives, quantifier meanings, operators, etc. This broad conception of ideology, which goes beyond just the predicates employed by a theory, is defended in Sider 2011.

${ }^{6}$ This latter point is true only assuming that parthood (or any other two place mereological primitive - proper parthood, overlap, etc.) is not of the same ideological kind as some ideological commitment which nihilists already accept. Cowling (2013: §8) argues that parthood and identity are of the same ideological kind. I think Cowling's incorrect, but I don't have the space here to consider his arguments.
} 


\section{Objection 3: Law parsimony.}

One respect in which a theory can be more or less parsimonious is with respect to the laws posited by the theory, both the number of laws posited by the theory, and the complexity of those laws (I don't have the space here to work out precisely what it would amount to for a law to be more or less complex, but we can leave it at an intuitive level). One argument against both property and substance dualism (going back at least to Smart 1959) is that dualists will need to posit fundamental psycho-physical laws correlating physical brain states with mental states. Insofar as the dualist must posit such laws, while the non-dualist does not, dualism is less parsimonious than its rivals. That's a strike against dualism.

Those who believe in composition will have to posit fundamental mereological laws, or, if you're not comfortable calling them "laws," fundamental principles regarding the manner in which composition works. ${ }^{7}$ These include, for example, whether or not the weak supplementation principle is (non vacuously) true, whether two composite objects can share all of the same proper parts, as well as, crucially, supervenience and explanatory relations between the properties of wholes and the properties of their proper parts (what van Inwagen calls "principles of composition" - van Inwagen 1990: 43). The supervenience relationship between wholes and their proper parts is generally taken for granted - isn't it just obvious, for example, that a whole would be located where its proper parts are located? On reflection, however, it should be seen as somewhat odd that the properties of this object (some whole) and the properties of those objects (the proper parts) are correlated in some respects, but not others. After all, contra proponents of composition as identity, wholes are distinct objects from their proper parts (taken individually or collectively), and widespread and systematic supervenience relationships between distinct objects cry out for explanation. Some philosophers (e.g. Cameron 2014) have admitted that the supervenience relationships between parts and wholes are brute. In any case, if you believe in composition, and you (like almost every other person who believes in composition) think that the properties of some wholes are correlated with the properties of their proper parts, then you'll need to posit fundamental laws governing the relationship between wholes and their parts. Insofar as the believer in composition needs to posit such laws, while the nihilist does not,

\footnotetext{
${ }^{7}$ Whether we call them "laws" or "principles" seems to me to be a superficial matter regarding how we use our words, and I only note the distinction here because some readers of this paper have been uncomfortable calling the principles in question "laws." The important point to note is that the mereological laws or principles are objectionable (if they are objectionable) for precisely the reason psycho-physical laws would be objectionable, namely insofar as they increase the complexity of our total theory.
} 
nihilism is more parsimonious than its competitors, and so is more likely to be true. ${ }^{8}$

It may be objected at this point that the sorts of mereological laws posited by the believer in composition are necessary, while the psycho-physical laws posited by the dualist are contingent, and this gives us some reason to think the law parsimony objection to dualism is a more powerful objection than the similar objection to composition. ${ }^{9}$ There are several problems with this objection. First, there seem to me to be no very compelling grounds for thinking mereological laws will all be necessary, or for that matter that the dualist's psycho-physical laws need be contingent. Second, it is unclear why contingent laws would count against a theory's parsimony more than necessary laws. If the dualist stipulated that his laws were necessary would that do anything to assuage our concern that those laws are unparsimonious? More generally, if we're concerned that some theoretical posit is unparsimonious, would it help assuage our concerns if the proponents of those theoretical posits stipulated that they are necessary rather than contingent? I think the answer to both these questions is "no." Both the dualist and the non-nihilist have to posit, for example, seemingly brute correlations between distinct objects (souls and bodies, parts and wholes), and insofar as they have to posit such laws it seems as if those of us who do not need to posit such mysterious and seemingly inexplicable correlations thereby make do with a simpler picture of the world. Whether the correlations posited by the dualist or nonnihilist are necessary or contingent seems to me to have nothing much to do with the fact that those of us who do not need to posit such correlations thereby have a simpler world view.

\section{Objection 4: Causal closure/exclusion.}

A popular argument against (interactionist versions of) substance dualism is based on the alleged causal closure of the physical world, or (another way of putting it) the exclusion of immaterial minds' causal influence from the physical world (see e.g. Kim 2005). If (interactionist) substance dualism is correct, then immaterial minds sometimes causally influence physical events. But every physical event which has a sufficient cause has a sufficient physical cause. So, barring overdetermination, immaterial minds never interact with physical events, and so (interactionist) substance dualism is false.

The parallel argument against composite objects is fairly well known, as a variant of that argument was defended in an influential book by Merricks

\footnotetext{
${ }^{8}$ Elsewhere (Brenner 2015b) I defend nihilism in part on the basis of the fact that nihilism is more parsimonious than its rivals insofar as it does not require that we posit mereological laws.

${ }^{9}$ Thanks to Chad Marxen for this objection.
} 
(2003). ${ }^{10}$ The idea is that the causal closure of the physical is no more plausible than the causal closure of the microphysical. In other words, every physical event which has a sufficient cause has a sufficient microphysical - and in particular, mereologically simple - cause. So, any causal contribution made by a composite object would be overdetermined by the causal contributions of its mereologically simple proper parts. The classic example is that of a baseball breaking a window. If the baseball moving in such-and-such a direction, with such-and-such a velocity relative to the window, is sufficient to break the window, then the mereologically simple constituents of the baseball, moving in such-and-such a direction, with such-and-such a velocity relative to the window, is sufficient to break the window. So, barring overdetermination, the baseball does not break the window. If these were good grounds to eliminate souls from our ontology, then they should also be good grounds to eliminate composite objects from our ontology. In fact, if composite objects are epiphenomena, we might have better grounds to eliminate them from our ontology than to eliminate epiphenomenal souls from our ontology. After all, if composite objects are epiphenomena, then it is difficult to see how we could ever learn of their existence via straightforward perceptual evidence, and such evidence is, I suspect, behind many people's insistence that composite objects exist ("I can just see my dog!") (cf. Dorr 2002: 65).

Merricks, of course, thinks some composite objects engage in causal relations which are not overdetermined by their proper parts. Perhaps Merricks is correct. But note that if this aspect of Merrick's view has any plausibility, it is unclear why the substance dualist should not be able to make a similar point, and argue that some immaterial objects (namely, souls) engage in causal relations which are not overdetermined by any physical causes.

Objection 5: No interaction between physical and non-physical; The pairing problem.

One popular objection to dualism is based on the alleged difficulty involved in an immaterial thing (a soul) engaging in causal interaction with a physical thing (the body associated with a soul). Here's how Paul Churchland puts it:

If 'mind-stuff' is so utterly different from 'matter-stuff' in its nature - different to the point that it has no mass whatever, no shape whatever, and no position anywhere in space - then how is

\footnotetext{
${ }^{10} \mathrm{I}$ don't make any effort to follow the precise manner in which Merricks presents the problem for composition. Dorr (2002: Ch.2) also gives this sort of argument against the existence of composite objects. While Merricks take his argument to count against the existence of most, but not all, composite objects, Dorr takes his argument to count in favor of full blown nihilism.
} 
it possible for my mind to have any causal influence on my body at all? ... How is this utterly insubstantial 'thinking substance' to have any influence on ponderous matter? How can two such different things be in any sort of causal contact? (Churchland 1984: 8-9)

As it stands, this isn't really an argument. (As Churchland notes later in his book (in a different context) "Rhetorical questions ... do not constitute arguments" (Churchland 1984: 16).) The most prominent attempt to make the challenge for substance dualism more concrete is Jaegwon Kim's "pairing problem" (see in particular Kim 2005: Ch. 3). Jim and Bob are both immaterial souls. Jim causes events in Jim's body, but not Bob's body. Why is that the case? This question is particularly pressing if we suppose that Jim and Bob are intrinsic duplicates - they both will, for example, that Jim's body raise its right hand. Why is it the case that Jim's intention to raise his right hand is causally efficacious, that it actually results in Jim's body raising its right hand, while Bob's intention is not causally efficacious? More generally, why is it the case Jim regularly causes changes in Jim's body, Bob regularly causes changes in Bob's body, and not vice-versa? What feature of the situation makes it the case that Jim is causally paired with Jim's body, rather than some other physical object?

These are still, of course, just rhetorical questions, but on reflection it may appear that the substance dualist can give no satisfying answer to these questions. When the relata of some causal relation are both spatially located we can say why they are causally related to one another - it is Jim's body which pets the dog, rather than Bob's body which pets the dog, because Jim's hand (a part of his body) is spatially contiguous (more or less) with the dog, while Bob's body is not. We can't tell any similar story about the causal relation between Jim and Jim's body, since Jim, being an immaterial soul, is not spatially located.

One way to ensure that Jim causes events in Jim's body, but not any other physical objects, is to posit some sort of primitive pairing relation between Jim and his body. This "solution" to the causal pairing problem effectively denies a metaphysical principle Kim tacitly employs, according to which causal relations can't be primitive, that there has to be some noncausal relation between causal relata which "pairs" the relata.

Even if we grant that causal relations don't need to be "paired" in the manner suggested by Kim, is positing a primitive pairing relation between souls and bodies really such a good idea? It seems to leave us with a more general pairing problem: why is this Jim's body, rather than, say, Bob's body? Why does the primitive pairing relation hold between Jim and Jim's 
body, rather than some other body? It's unsatisfying (we can suppose) that this soul would be associated with this body by mere chance, for no reason at all. One proposed solution to the problem (defended by Swinburne 1986: 198-199) is that souls are associated with their respective bodies because God decrees that they are associated with one another. Another solution is that souls are spatially located (Hasker 1999). This might provide a solution to the pairing problem, since we could say that this soul is associated with this body because it is located where this body (or some part of this body) is located. Or perhaps this soul is associated with this body because it is the activities of this body which give rise to, ground, or create this soul (cf. Bailey et. al. 2011: 353).

There is an analogous problem for composition: why is this whole associated with these parts? ${ }^{11}$ Why is it the case that these parts compose this table, rather than some other qualitatively identical table? These questions are particularly pressing for those who believe that some objects can compose some composite object at one time, and those very objects can compose an entirely different composite object at some other time. ${ }^{12}$ Again, it would be unsatisfying if there was no explanation at all for the association. Any solution open to the dualist is also available to the believer in composition: perhaps God decides which wholes are associated with which parts, or perhaps wholes are associated with their parts because they are located where those parts are located, or perhaps this whole is associated with these parts because these are the parts which give rise to, ground, or create this whole. If any of these solutions to the mereological pairing problem work, then presumably the analogous solutions with respect to the dualist pairing problem should work as well.

I suspect that some readers will think the natural and obvious response to the mereological pairing problem is that parts are associated with their respective whole because they are located within the region in which the whole is located. ${ }^{13}$ This response will perhaps be considered so obvious that the mereological pairing problem will not be seen as a "problem" at all. Allow me to make two observations, intended to underscore the fact that this proposed solution to the mereological pairing problem is not as obviously correct as its proponents might assume. First, if we say that parts are associated with their wholes because they are located within the region occupied by their wholes, then we will rule out as impossible certain sorts of constitution. Some philosophers have wanted to say, for example, that some

\footnotetext{
${ }^{11}$ This "mereological pairing problem" was introduced in Brenner 2015b.

12 Just as the analogous pairing problem for dualism might be particularly acute for substance dualists who believe in reincarnation.

${ }^{13}$ Thanks here to an anonymous referee.
} 
object $\mathrm{A}$ is located within the region occupied by composite objects $\mathrm{B}$ and $\mathrm{C}$, and while $\mathrm{A}$ is a part of $\mathrm{B}$, it is not a part of $\mathrm{C}$. Think, for example, of a statue which is colocated (and constituted by) a lump of clay: the arm of the statue (say) may be part of the statue, but not part of the lump, despite the fact that it is located within the region occupied by both the statue and the lump. A second point to note is that if we answer the mereological pairing problem by saying that some parts are associated with their whole because they are located within the region occupied by the whole, then we will simply have traded one demand for explanation (why are these parts associated with these wholes?) with another (why are parts always locate within the region occupied by their wholes?).

You might think the pairing problem for dualism is more serious than the pairing problem for composition, for the following reason: souls can exist without their bodies, but wholes cannot exist without their parts. ${ }^{14}$ I have several responses to this concern. First, it does not seem as if it does anything to undermine the worry behind the pairing problem, namely that you will have to posit some sort of mysterious or otherwise objectionable primitive pairing relation between souls and bodies, or wholes and parts. Whether wholes must have parts if they are to exist, or even whether wholes must have some particular parts if they are to exist, does nothing to undermine the suspicion that there is an explanatory burden which must be met to explain why this whole is associated (perhaps essentially) with these parts. Leaving that point aside, however, I would also question the assumption that wholes must invariably have (proper) parts in order to exist. ${ }^{15}$ If wholes must have parts in order to exist, then wholes are wholes essentially. But I don't see any motivation for thinking wholes are wholes essentially. Conversely, if we suppose that wholes are wholes essentially, we should also feel free to suppose that souls are essentially such that they have some body or other. Some substance dualists (e.g. Hasker 1999), for example, see souls as "emerging" from their respective brains. Such dualists might very well think that souls can exist only if they remain associated with some brain or other.

I'll end my discussion of the pairing problem by briefly noting a second pairing problem for some believers in composite objects, one which regards the causal relations entered into by mereologically coincident objects. Some philosophers (e.g. Baker 2000) think there are composite objects which are such that one constitutes the other. Think, for example, of the statue and the lump of material which composes the statue. If mereologically coincident

\footnotetext{
${ }^{14}$ Thanks to an anonymous referee for suggesting I address this worry.

${ }^{15}$ Everything is trivially a part of itself, so it is true that any particular thing must have at least one part (itself) if it is to exist. So, what we're really wondering about here is whether wholes must have proper parts in order to exist.
} 
objects can exhibit different causal powers (as Baker believes), then, since they are colocated with one another, we'll be left with a causal pairing problem: why is it the case that this object caused this effect, while the object with which it is colocated, which exhibits the same spatio-temporal relation with the effect, did not cause that effect? ${ }^{16}$

\section{Objection 6: Conservation laws.}

One concern regarding interactionist variants of substance dualism is whether such views are compatible with conservation laws (e.g. mass/energy conservation, linear-momentum conservation). Let's focus on conservation of mass/energy. ${ }^{17}$ In particular, if a soul causes some event in the brain (perhaps, for example, the movement of my arm) wouldn't this involve some sort of transfer of energy to the brain, and wouldn't that result in a violation of relevant conservation laws? Here's how Dennett puts the worry:

No physical energy or mass is associated with [souls]. How, then, do they get to make a difference to what happens in the brain cells they must affect, if the mind is to have any influence over the body? A fundamental principle of physics is that any change in the trajectory of any physical entity is an acceleration requiring the expenditure of energy, and where is this energy to come from? ... This confrontation between quite standard physics and dualism has been endlessly discussed since Descartes's own day, and is widely regarded as the inescapable and fatal flaw of dualism (Dennett 1991: 35) $)^{18}$

Do conservation laws have any implications for what we should think about composite objects? Maybe. Consider theories according to which composite physical objects come into existence. On these views new physical composite objects come into existence, objects with mass, volume, etc. In such cases we have no reason to believe some corresponding amount of mass was destroyed. Why then wouldn't the total mass of a physical system in which a new composite object is included increase? Here's an example. Let's say you have $n$ simples, the total mass of which is, in some particular frame of reference (I'll suppress this detail from now on), 10kg. You put the simples

\footnotetext{
${ }^{16}$ The similarity between Kim's pairing problem and the analogous pairing problem for mereologically coincident objects is noted by Bennett (2007: 321) and Bailey et. al. (2011: 351-352).

${ }^{17}$ For a discussion of conservation of momentum, and whether such conservation laws would pose a problem for interactionist dualism, see Averill, Keating 1981.

${ }^{18}$ See Montero 2006: 384-385 for an extensive list of philosophers who argue against interactionist dualism on the basis of conservation laws.
} 
together in such a manner that they begin to compose a table, a table which will presumably have a mass of $10 \mathrm{~kg}$. Since the table is not identical with the simples of which it is composed, ${ }^{19}$ after we form the table we should presumably have objects whose mass totals $20 \mathrm{~kg}$ : the $10 \mathrm{~kg}$ of simples, plus the $10 \mathrm{~kg}$ table. But clearly enough, at the end of the process we only have objects whose total mass equals $10 \mathrm{~kg}$. What gives?

Here is a concern which you might, but shouldn't, have. When I suggest that we should expect to have objects whose total mass measures $20 \mathrm{~kg}$ after the simples compose the table, I am double counting: we measure the mass of the proper parts twice, first when we measure the mass of the proper parts, and then again when we measure the mass of the whole. ${ }^{20}$ In response I'd note that we do not measure the mass of the proper parts twice. When we measure the mass of the whole we are measuring the mass of the whole, not its proper parts, objects which are distinct from the whole. Of course, given the appropriate sorts of mereological laws or principles of composition, you might think the mass of the whole is determined by the mass of the proper parts. That may very well be true, but it wouldn't show that in measuring the mass of the whole and in measuring the mass of the proper parts we've measured the mass of the proper parts twice. Consider an analogy: My parents ensure that I get just as many pieces of candy as my brother gets. So, assuming my brother receives his candy first, then the number of pieces of candy which I get is determined by the number of pieces which my brother gets. It would not follow that you would be double counting if you counted my pieces and then counted my brother's pieces. After all, my pieces of candy are distinct objects from my brother's pieces of candy, despite the fact that the number of pieces I have is determined by the number of pieces my brother has, and so despite the fact that, in measuring my pieces, you can easily determine how many pieces my brother has. Similarly, insofar as a whole and its proper parts are distinct objects, in measuring the mass of a whole you do not thereby automatically measure the mass of its proper parts, even if by measuring the mass of the whole you can determine the mass of the proper parts.

I suspect this problem for composition will not be taken very seriously by many people, but I'm not sure why. Composition (physical composition, anyway) results in new physical objects, with non-zero masses. That should, prima facie, violate the conservation of mass/energy, and yet transparently that conservation law does not appear to be violated in cases of purported

\footnotetext{
${ }^{19}$ I assume throughout that composition as identity, according to which composite objects are identical with their parts, is false.

${ }^{20}$ Thanks to Chad Marxen for this objection.
} 
composition. There are two obvious responses to this concern: either composition doesn't occur after all, or you can create a new massive physical object, without removing or decreasing the mass of any other physical objects, without increasing the total mass of the total system of physical objects. The latter principle could legitimately be seen as an ad hoc emendation of the relevant conservation law. (And, as long as we're making ad hoc modifications to conservation laws, why couldn't the dualist make that move?)

Something like the problem I've just pressed for those who believe in composition has been discussed before in debates over constitution. Recall the lump which is alleged to constitute a statue. If the lump has a mass of $10 \mathrm{~kg}$, and the statue has a mass of $10 \mathrm{~kg}$, and the lump is not identical with the statue, then why is it the case that when we put the lump and statue on a scale the scale doesn't measure $20 \mathrm{~kg}$ (see, for example, Lewis 1986: 252)? Interestingly, Thomson (1998: 170, n.5) defends constitution from this sort of objection on the grounds that, if we wonder why the lump and statue don't collectively have a mass of $20 \mathrm{~kg}$, then we should also be led to wonder why the statue and any of its proper parts do not collectively have a mass which is the sum of the mass of the statue and the mass of that proper part. Thomson assumes the latter puzzle regarding the relationship between the mass of a composite object and the masses of its proper parts is unproblematic, but that is precisely the assumption which I've challenged above.

Objection 7: Mental properties supervene on physical properties in brains, so this is evidence that physical properties of brains are all there are.

A very popular objection to substance dualism is something like the following. We know that mental properties are supervenient upon physical brain states. What explains this supervenience relationship? The physicalist's response to this question is that mental states supervene on physical brain states because mental states just are physical brain states. Once we've got those physical brain states we don't have any reason to posit any further properties (irreducible mental properties) or substances (souls).

Sometimes proponents of this sort of objection to dualism write as if the dualist does not think that mental properties supervene on physical brain states (see e.g. Churchland 1984: 20). But that wouldn't be a very solid foundation for an objection to dualism, since dualists (obviously) can and do recognize widespread and systematic supervenience relationships between mental states and physical brain states. A better way to put the objection to dualism is that physicalism is a particularly elegant, but defeasible, explanation of the widespread and systematic supervenience between mental states and physical brain states. Alternatively, the objection might be put 
in probabilistic terms. Physicalism predicts that mental states will supervene on physical brain states, insofar as physicalism predicts that mental states are physical brain states. Dualism, by contrast, is compatible with mental states supervening on physical brain states, but does not entail that they do so. Accordingly, our evidence E (systematic supervenience of mental states on physical brain states) is more probable given the hypothesis $\mathrm{P}$ that physicalism is true than given the hypothesis $\mathrm{D}$ that dualism is true $(\operatorname{Pr}(\mathrm{E} / \mathrm{P})>\operatorname{Pr}(\mathrm{E} / \mathrm{D}))$. So, since physicalism is incompatible with dualism, the widespread systematic supervenience of mental states on physical brain states raises the probability of physicalism vs dualism.

Analogous points can be made with respect to composite objects. Properties of (alleged) wholes supervene on the properties of their proper parts. So, why posit the whole in addition to the parts? Once we've got the parts, why should we go any further and posit wholes which are associated with those parts? Put another way, given that the properties of whatever are in this region supervene on the properties of the simples in this region, a particularly elegant explanation of that supervenience is that the region in question only contains the simples. Put in probabilistic terms, nihilism predicts that the properties of whatever is in this region will supervene on the properties of the simples in this region, while by contrast if we reject nihilism there is no guarantee that the properties of whatever is in this region will supervene on the properties of the simples in this region. So, the systematic supervenience of the properties of whatever is in this region on the properties of the simples in this region provides evidence in favor of nihilism, since nihilism predicts that supervenience better than the negation of nihilism. If the former objection(s) to dualism works, then the exactly analogous objection(s) to composition should work as well (and vice versa).

You may be tempted to make the following response: the properties of whatever is in this region supervene on the simples in this region because the simples in this region are parts of whatever composite objects are in this region. ${ }^{21}$ But this response is only tenable if we posit laws governing the manner in which the properties of wholes supervene on the properties of their proper parts. The dualist can make the same move, saying that the properties of souls supervene on the properties of brains in certain respects because of psycho-physical laws.

\section{Objection 8: Evolutionary debunking.}

There is mounting evidence which suggests that humans are naturally disposed to be mind/body dualists (cf. Bloom 2004; Bering, Bjorklund 2004; Hood, et. al. 2012; Forstmann, Burgmer 2015). So, it seems as if we might

\footnotetext{
${ }^{21}$ Thanks to an anonymous referee for suggesting I address this response.
} 
have built-in cognitive faculties which dispose us toward dualism. If we have no reason to think such cognitive mechanisms are reliable, then we might have the resources to develop an evolutionary debunking argument against dualism, of the sort which has recently received a great deal of attention in meta-ethics (see e.g. Street 2006; Joyce 2006). ${ }^{22}$ Any plausible argument of this sort would not, I think, actually show that dualism lacks epistemic justification. It might, however, undermine particular sources of justification for dualism (cf. Jong, Visala 2014), insofar as it might show that the sorts of intuitions which underlie arguments for dualism are of dubious reliability. These include, for example, the sorts of modal intuitions which underlie conceivability arguments for substance dualism (in e.g. Swinburne 1986: Ch.8; Plantinga 2006).

Similar points can be made with respect to our belief in composite objects. There is little doubt that humans have an innate tendency to believe in composite objects (for details, see Osborne 2016). Is there any reason to think those cognitive faculties by which we acquire such beliefs are reliable? Plausibly not, insofar as a world in which there are no composites will arguably be empirically identical to one in which there are composite objects, or at the very least empirically identical with respect to those situations we can expect our evolutionary predecessors to have encountered. There is no reason, then, to think there would have been any evolutionary pressure toward our forming or retaining reliable cognitive faculties by which we form the belief that there are composite objects. So, insofar as our belief in composite objects is the result of cognitive faculties which we have no reason to believe are reliable, we have reason to withdraw those beliefs. And it's interesting to note that almost without exception philosophers defend belief in composition on the basis of intuition and perception - those very cognitive faculties which we have no reason to think are reliable with respect to this subject matter (that is, with respect to whether or not there are composite objects in any particular vicinity, rather than merely simples arranged in some particular manner).

Objection 9: Where do souls come from?

One challenge for substance dualists is to explain where souls come from. ${ }^{23}$ Presumably the souls which exist now haven't always existed. So, by what causal mechanism did they come to exist? A more specific way of putting the worry is in terms of our evolutionary history. Presumably at some point in our evolutionary history there weren't any souls, but now there are. Assuming it can't be a vague matter whether souls exist or are associated with

\footnotetext{
${ }^{22}$ For a more general discussion of evolutionary debunking arguments, see Kahane 2011.

${ }^{23}$ For a recent discussion of this subject see Farris 2014.
} 
particular bodies, then at some point there was a sharp cut off - before that point there were no souls, but after that point there were. So, by what casual mechanism was that gap bridged? And is it really so plausible to suppose there would be any sharp cut off point of this sort, when our evolutionary history was a very gradual sort of process?

Admittedly, it's difficult to turn these worries into any sort of argument against dualism. Still, you might think it is implausible that there could be sharp cut off points, in the history of individual organisms or in the history of life more generally, before which there is no soul, and after which there $i s$ a soul. So, if the dualist is committed to such cut off points, then she's in trouble. More generally, you might think it's very mysterious that new souls come into existence when new organisms (or human organisms specifically) come into existence. Assuming that we understand the sorts of biological processes involved in the creation of a new organism, why should any of that result in a new immaterial soul? The creation of a new soul in this sort of situation seems utterly inexplicable.

A similar challenge is faced by many of those who believe in composition: where do composite objects come from? In particular, non-universalists will have to embrace sharp cut off points, precise configurations of matter (for example) which are such that before that configuration is in place there is no composite object, but after that configuration is in place there is. This is assuming, of course, that it cannot be vague whether some composite object exists in some particular situation. But such vagueness is widely regarded as implausible, insofar as it plausibly leads to vagueness with respect to how many objects there are. ${ }^{24}$ Leaving aside the concern about cut off points, you might think the generation of new physical composite objects is very mysterious. For example, most people who believe in composite objects apparently think I can create a brand new large physical object, one so heavy I can't even carry it, just by moving other objects around. I take some pieces of wood and I move them around, and I nail them together. I've made a table. Suddenly a large physical object, one which hasn't existed until this moment, stands before me. Why did that happen? How did I make a whole new large heavy physical object just by moving some other objects around and putting nails in them? This seems utterly inexplicable, maybe even magical.

For what it's worth, perhaps neither objection (the objection to dualism or the parallel objection to composition) is particularly compelling. Where do

\footnotetext{
${ }^{24}$ But for one (kind of weird) way to try to avoid the conclusion that vagueness with respect to when composition occurs will lead to vagueness with respect to how many objects exist, see Carmichael 2011.
} 
composite objects come from? Presumably, the answer will be that they show up when some mereological simples exhibit certain properties (for example, when they're arranged in a certain manner). We could say something similar about souls - they show up when the bodies with which they are associated instantiate certain properties (for example, when they develop brains of a certain configuration). In both cases we'll need laws governing the creation of the new objects in question, i.e., laws of the form "when such-and-such sorts of simples instantiate such-and-such a property then they begin to compose a table."

In any case, it seems to me that if this is a challenge for substance dualists, it's a challenge for those who believe in composition as well, and vice versa. We only have a distinctive problem for substance dualism if the difficulty is really the purported difficulty of making sense of causal interaction between physical things and non-physical things (e.g. a physical thing causing a soul to come into existence). But that's a different objection.

\section{Implications}

I've argued that all of the popular arguments against substance dualism have parallel arguments against composition. What's more, I have argued that if you accept any of these arguments against substance dualism then you should accept the parallel argument against composition. In the course of setting out all of the popular arguments against substance dualism I have, coincidentally, presented all of the most popular arguments against composition (as well as some unpopular or entirely novel arguments against composition). So, I have in effect argued that all of the most popular arguments against composition have parallel arguments against substance dualism. And while I have been mostly concerned to establish the claim that if you accept any of the arguments against substance dualism discussed above then you should accept the parallel argument against composition, I think the converse claim is plausible as well: if you accept any of the arguments against composition discussed above, then you should accept the parallel argument against substance dualism.

These theses, if correct, should be of intrinsic interest. However, they also have important implications for how we evaluate both mereological nihilism and substance dualism, and in this section I'll explore what those implications might be. There are at least two major implications of these theses which I will explore here. First, that those who reject substance dualism may have reason to reject composition (and vice versa). Second, that one major objection to nihilism, what I call the "composite persons objection" 
to nihilism, is unsuccessful. I'll discuss each of these subjects in turn.

It may seem as if it is a small step from "if you accept one of these popular arguments against substance dualism then you should accept a parallel argument against composition (and vice versa)" to "if you reject substance dualism then you should reject composition (and vice versa)." But this isn't so obvious. For starters, you might reject substance dualism, or reject composition, for some unconventional reason which I haven't discussed. Or, you might think it is obvious or otherwise probable that composition occurs. Accordingly, you will put little if any stock in the objections to composition which I've discussed above. If this is your view, then perhaps this paper will lead you to put little stock in the parallel objections to dualism, now that you've seen how all of the objections to composition which I've discussed above can, with little modification, be turned into objections to dualism. Another prima facie reasonable response to this paper is to note that, since you already find one or more of the popular objections to dualism convincing, you will find the parallel objection(s) to composition convincing as well. Accordingly, you will lower the epistemic probability you accord to the view that composition occurs. Or, perhaps the objections discussed above will lead you to place less credence in the disjunction of dualism and the view that composition occurs. ${ }^{25}$

In any case, an important take away is that, surprisingly, how one evaluates substance dualism will have major implications for how one evaluates nihilism, and conversely how one evaluates nihilism will have major implications for how one evaluates substance dualism. At least for many people, the following conjunctions of views may be dialectically unstable:

(1) Reject composition and accept substance dualism.

(2) Reject substance dualism and accept composition.

Note that I am not making the strong claim that if, e.g., nihilism is true, then substance dualism is false. There isn't a straightforward entailment relation, in either direction, between the former thesis (nihilism is true) and the latter thesis (substance dualism is false). Rather, I am making the weaker claim that if, say, you accept nihilism, and also accept substance dualism, then you have some explaining to do. In particular you will have to answer the challenge "if you reject composition on the basis of such-and-such arguments, why don't parallel arguments lead you to reject substance dualism?"

That (2) may represent an unstable conjunction of views seems to me to have a particularly noteworthy implication, namely that it undermines what I will call the "composite persons objection to nihilism" (or just the CPO).

${ }^{25}$ Thanks here to Liz Jackson. 
Here's how van Inwagen puts the CPO: “... Nihilism would appear to be false, for you and I exist and we are composite objects" (van Inwagen 1990: $73) .^{26}$

This is, I think, the most powerful objection which has so far been raised against nihilism, but it is one which nihilists have not taken very seriously. For example, in Sider's recent defense of nihilism (Sider 2013) he devotes 43 pages to responding to objections to nihilism, but only one of those pages is about the CPO. Other nihilists are similarly brief in their responses to the argument. ${ }^{27}$ The response given by Sider and others is, more or less, that we don't exist, and that phenomenal states are collectively instantiated by whatever simples are commonly thought to compose us or our brains. I don't think this response is very satisfying. Many of us are rightly skeptical of the notion that we don't exist, so it would be worthwhile if the nihilist had an alternative response to the CPO.

There is a fairly obvious response for the nihilist to make: If I exist, and, as nihilists contend, composition never occurs, then I must be something other than a composite object. There are several options here. Perhaps I am some (non-composite) stuff, or an arrangement of simples/stuff (Goldwater 2015), or I am a simple. The last option, in the form of a variant of substance dualism according to which I am a mereologically simple non-physical object, has historically been quite popular. Many philosophers seem to suppose that if nihilism is true, and we exist, then some sort of substance dualism must be correct, since it gives us the only plausible way to respond to the CPO.

Unfortunately for the nihilist, substance dualism is not very popular among philosophers today. It is this fact which provides the key to a novel response to the CPO, since, as I've argued above, all of the popular arguments against substance dualism can, with minor modifications, be transformed into arguments against composition. Some people reject nihilism because they reject substance dualism, and think nihilists need to be committed to substance dualism in order to get around the CPO. One upshot of this paper is that you should probably not endorse that line of thought - you should probably not reject nihilism because you reject substance dualism. Put another way, the CPO (the conclusion of which is that nihilism is false) relies on the presupposition that substance dualism is false. But all of the popular arguments for that presupposition can, with only minor modifications, be transformed into arguments against the conclusion of the CPO. So, you shouldn't endorse the CPO (unless, of course, you reject substance dualism

\footnotetext{
${ }^{26}$ Other philosophers who give this sort of objection to nihilism include Markosian 1998; Hudson 2001: Ch.1; Olson 2007: Ch.9; Gilmore ms.

${ }^{27}$ For example, Dorr and Rosen 2002 also devote about a page to the CPO.
} 
for some reason other than one of the reasons discussed above). At the very least I'm shifting the burden of proof to those who reject nihilism because they reject substance dualism: If you reject substance dualism, why don't your arguments against substance dualism (with minor modifications) also imply that composition never occurs?

I'll end my discussion of the CPO with a list of some of the philosophers I have in mind here - that is, philosophers who rejects nihilism because they reject substance dualism. Hud Hudson considers the "Problem of the Many," a puzzle regarding composition which I don't need to describe in too much detail in order to get my point across. The Problem of the Many aims to show that we run into trouble if we follow our pre-theoretic beliefs regarding which sorts of relatively large composite objects exist. One way out of the difficulty, one which the nihilist is happy to accept, is to deny the existence of the composite objects which cause the trouble. Hudson says we should reject this solution to the Problem of the Many because it would entail that we don't exist, since we're relatively large composite objects if we exist (Hudson 2001: 17-18). Hudson quickly concedes that substance dualists can avoid quantifying over large-ish composite objects, without resorting to the view that we don't exist (Hudson 2001: 19-21). Unfortunately for the would-be dualist, her solution to the Problem of the Many runs into its own problems, chief among them being the "traditional objections to Dualism" (Hudson 2001: 21). Hudson does not tell us what these "traditional objections to Dualism" are, but if I had to guess he had in mind some of the arguments I discuss above. So, Hudson advocates the theoretical position which I suggest in this paper is unstable: he advocates that we reject nihilism because, barring her adoption of the particularly implausible view that we don't exist, the nihilist will have to be a substance dualist, and he advocates that we reject substance dualism because of the "traditional objections." This view is unstable because those "traditional objections" can, with little modification, be turned into arguments in favor of nihilism. Ned Markosian (to give another example) is in a similar predicament. Markosian tells us that one of the serious difficulties facing nihilism is that nihilism would entail that we don't exist, since we "are surely physical objects composed of many parts, if we exist at all" (Markosian 1998: 220). He concedes that one way out of the difficulty would be to accept substance dualism, but substance dualism is "unacceptable" (Markosian 1998: 245, Note 23). Markosian does not tell us why substance dualism is unacceptable, but it would be unsurprising if he rejects substance dualism because of one or more of the popular objections to dualism discussed above. To give one final example, Cody Gilmore (ms) has developed a version of the CPO which includes as a premise "If I have being, then I am composite." Gilmore recognizes that substance dualism is 
incompatible with this premise, but says that we should reject substance dualism because "we have (partly empirical) grounds for denying that there are souls or other concrete non-physical entities." Gilmore does not elaborate, but I assume that the objections to substance dualism which he has in mind are some or all of those objections which I discuss in $\S 2$.

\section{Conclusion}

I don't pretend that I've surveyed every prima facie plausible argument against substance dualism, or every prima facie plausible argument against composition. I have, I think, surveyed all of the most popular arguments against substance dualism and composition. I've shown that how one evaluates substance dualism will be tied up with how one evaluates mereological nihilism, since the most popular arguments against substance dualism all have parallel arguments against composition. Another interesting upshot of all of this is, again, that you should probably not endorse the CPO. The $\mathrm{CPO}$ only works if substance dualism is false (that substance dualism is false is a presupposition of the argument), and if composition occurs (this is the conclusion of the argument). But those arguments which are most likely to lead you to reject substance dualism can, with minor modifications, be transformed into objections to composition.

Here is a final issue. I've argued that every popular objection to dualism has a parallel objection to composition. Given that dualism is unpopular because of these sorts of objections, why is composition not similarly unpopular? I have two things to say on this subject.

First, the parallels between objections to substance dualism and objections to composition have, for the most part, been overlooked.

Second, most people think we have a strong positive case to make for composition, while we do not have a similarly strong case to make for the existence or causal efficacy of immaterial souls. I don't have the space here to examine positive arguments for composition (or, for that matter, positive arguments for substance dualism). Let me register my conviction, however, that such arguments are generally very weak. The most popular defenses of composition rely on appeals to "common sense," widespread belief in composition (the consensus gentium argument for composition), alleged perception of composite objects, phenomenal conservatism, and the fact that belief in composition is more "intuitive" than nihilism. These seem to me to be fairly weak grounds for belief in composition, and ironically enough almost all of these arguments could be marshaled in service of substance dualism. Arguments for composition on the basis of its role in science are more defensible, 
but, I think, ultimately unsuccessful, although that is a topic for another occasion (see Brenner forthcoming). ${ }^{28}$

\section{References}

[1] Luke Van Horn Andrew M Bailey, Joshua Rasmussen. No pairing problem. Philosophical Studies, 154:349-360, 2011.

[2] Lynne Rudder Baker. Persons and Bodies: A Constitution View. Cambridge University Press, 2000.

[3] Karen Bennett. Mental causation. Philosophy Compass, 2(2):316-337, 2007.

[4] Karen Bennett. Composition, colocation, and metaontology. In David J. Chalmers, David Manley, and Ryan Wasserman, editors, Metametaphysics, pages 38-76. Oxford University Press, Oxford, 2009.

[5] Paul Bloom. Descartes' Baby: How the Science of Child Development Explains What Makes Us Human. Basic Books, 2004.

[6] Andrew Brenner. Mereological nihilism and the special arrangement question. Synthese, 192(5):1295-1314, May 2015.

[7] Andrew Brenner. Mereological nihilism and theoretical unification. Analytic Philosophy, 56(4):318-337, December 2015.

[8] Andrew Brenner. Science and the special composition question. Synthese, Forthcoming.

[9] Paul Bloom Bruce Hood, Nathalia L. Gjersoe. Do children think that duplicating the body also duplicates the mind? Cognition, 125:466-474, 2012.

[10] Ross P. Cameron. Parts generate the whole, but they are not identical to it. In Donald Baxter and Aaron Cotnoir, editors, Composition As Identity, pages 90-107. Oxford University Press, Oxford, 2014.

\footnotetext{
${ }^{28}$ Thanks to Aaron Creller, Peter Finocchiaro, Liz Jackson, Chad Marxen, Jonathan Matheson, Sarah Mattice, Callie Phillips, Michael Rea, Bradley Rettler, Raphael Mary Salzillo, Peter van Inwagen, the audience at my presentation of this paper at the 2016 American Philosophical Association Pacific Division meeting, and two anonymous referees for very helpful comments on earlier drafts of this paper.
} 
[11] Chad Carmichael. Vague composition without vague existence. Nô̂s, 45(2):315-327, June 2011.

[12] Paul Churchland. Matter and Consciousness. MIT Press, 1984.

[13] Sam Cowling. Ideological parsimony. Synthese, 190(17):3889-3908, 2013.

[14] Daniel C. Dennett. Consciousness Explained. Back Bay Books, 1991.

[15] Cian Dorr. The Simplicity of Everything. PhD thesis, Princeton University, 2002.

[16] Cian Dorr and Gideon Rosen. Composition as a fiction. In Richard Gale, editor, The Blackwell Guide to Metaphysics, pages 151-74. Blackwell, Oxford, 2002.

[17] B. F. Keating Edward Averill. Does interactionism violate a law of classical physics? Mind, 90(357):102-107, January 1981.

[18] Joshua R. Farris. Emergent creationism: Another option in the origin of the soul debate. Religious Studies, 50:321-339, 2014.

[19] Cody Gilmore. A cartesian argument against compositional nihilism.

[20] Jonah P. B. Goldwater. No composition, no problem: Ordinary objects as arrangements. Philosophia, 43(2):367-379, 2015.

[21] William Hasker. The Emergent Self. Cornell University Press, 1999.

[22] Terence Horgan and Matjaž Potrč. Austere Realism: Contextual Semantics Meets Minimal Ontology. The MIT Press, Cambridge, 2008.

[23] Hud Hudson. A Materialist Metaphysics of the Human Person. Cornell University Press, Ithaca, NY, 2001.

[24] David F. Bjorklund Jesse M. Bering. The natural emergence of reasoning about the afterlife as a developmental regularity. Developmental Psychology, 40(2):217-233, 2004.

[25] Aku Visala Jonathan Jong. Evolutionary debunking arguments against theism, reconsidered. International Journal for Philosophy of Religion, 76(3):243-258, December 2014.

[26] Richard Joyce. The Evolution of Morality. MIT Press, 2006. 
[27] Guy Kahane. Evolutionary debunking arguments. Noûs, 45(1):103-125, March 2011.

[28] Jaegwon Kim. Physicalism, or Something Near Enough. Princeton University Press, Princeton, 2005.

[29] David Lewis. On the Plurality of Worlds. Blackwell, Oxford, 1986.

[30] Ned Markosian. Brutal composition. Philosophical Studies, 92:211-49, 1998.

[31] Pascal Burgmer Matthias Forstmann. Adults are intuitive mind-body dualists. Journal of Experimental Psychology: General, 144(1):222-235, 2015 .

[32] Trenton Merricks. Objects and Persons. Clarendon Press, Oxford, 2003.

[33] Barbara Montero. What does the conservation of energy have to do with physicalism? Dialectica, 60(4):383-396, 2006.

[34] Eric T. Olson. What Are We? A Study in Personal Ontology. Oxford University Press, 2007.

[35] Robert Carry Osborne. Debunking rationalist defenses of common-sense ontology: An empirical approach. Review of Philosophy and Psychology, 7(1):197-221, March 2016.

[36] Alvin Plantinga. Against materialism. Faith and Philosophy, 23(1):3-32, 2006.

[37] W. V. O. Quine. Ontology and ideology. Philosophical Studies, 2:11-15, 1951.

[38] Theodore Sider. Writing the Book of the World. Clarendon Press, Oxford, 2011.

[39] Theodore Sider. Against parthood. In Karen Bennett and Dean W. Zimmerman, editors, Oxford Studies in Metaphysics, volume 8. Oxford University Press, Oxford, 2013.

[40] J. J. C. Smart. Sensations and brain processes. Philosophical Review, 68:141-56, 1959.

[41] Sharon Street. A Darwinian dilemma for realist theories of value. Philosophical Studies, 127:109-66, 2006. 
[42] Richard Swinburne. The Evolution of the Soul. Oxford University Press, Oxford, 1986.

[43] Jonathan Tallant. Against mereological nihilism. Synthese, 191:1511$1527,2014$.

[44] Judith Jarvis Thomson. The statue and the clay. Nô̂s, 32:149-73, 1998.

[45] Peter van Inwagen. Material Beings. Cornell University Press, Ithaca, NY, 1990. 